\title{
Bacterial etiology of community-acquired pneumonia in immunocompetent hospitalized patients and appropriateness of empirical treatment recommendations: an international point-prevalence study
}

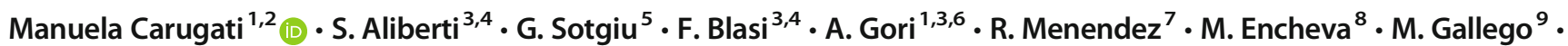 \\ P. Leuschner ${ }^{10}$. S. Ruiz-Buitrago ${ }^{11}$. S. Battaglia ${ }^{12} \cdot$ R. Fantini $^{13}$. S. Pascual-Guardia ${ }^{14}$. J. Marin-Corral ${ }^{15}$. \\ M. I. Restrepo ${ }^{16} \cdot$ GLIMP Collaborators
}

Received: 15 January 2020 / Accepted: 18 March 2020 / Published online: 3 April 2020

(C) Springer-Verlag GmbH Germany, part of Springer Nature 2020, corrected publication 2021

\begin{abstract}
An accurate knowledge of the epidemiology of community-acquired pneumonia (CAP) is key for selecting appropriate antimicrobial treatments. Very few etiological studies assessed the appropriateness of empiric guideline recommendations at a multinational level. This study aims at the following: (i) describing the bacterial etiologic distribution of CAP and (ii) assessing the appropriateness of the empirical treatment recommendations by clinical practice guidelines (CPGs) for CAP in light of the bacterial pathogens diagnosed as causative agents of CAP. Secondary analysis of the GLIMP, a point-prevalence international study which enrolled adults hospitalized with CAP in 2015. The analysis was limited to immunocompetent patients tested for bacterial CAP agents within $24 \mathrm{~h}$ of admission. The CAP CPGs evaluated included the following: the 2007 and 2019 American Thoracic Society/Infectious Diseases Society of America (ATS/IDSA), the European Respiratory Society (ERS), and selected country-specific CPGs. Among 2564 patients enrolled, 35.3\% had an identifiable pathogen. Streptococcus pneumoniae (8.2\%) was the most frequently identified pathogen, followed by Pseudomonas aeruginosa (4.1\%) and Klebsiella pneumoniae (3.4\%).
\end{abstract}

Electronic supplementary material The online version of this article (https://doi.org/10.1007/s10096-020-03870-3) contains supplementary material, which is available to authorized users.

Manuela Carugati

ela.carugati@gmail.com

1 Internal Medicine Department, Division of Infectious Diseases, Fondazione IRCCS Cà Granda Ospedale Maggiore Policlinico Milano, Milan, Italy

2 Division of Infectious Diseases and International Health, Duke University, Durham, USA

3 Department of Pathophysiology and Transplantation, Università degli Studi di Milano, Milan, Italy

4 Internal Medicine Department, Respiratory Unit and Adult Cystic Fibrosis Center, Fondazione IRCCS Cà Granda Ospedale Maggiore Policlinico Milano, Milan, Italy

5 Clinical Epidemiology and Medical Statistics Unit, Department of Medical, Surgical and Experimental Sciences, University of Sassari, Sassari, Italy

6 Centre for Multidisciplinary Research in Health Science, Milan, Italy

7 Pneumology Service, University and Polytechnic Hospital La Fe, Valencia, Spain
8 Clinic of Pulmonary Diseases, Military Medical Academy, Sofia, Bulgaria

9 Department of Respiratory Medicine, Hospital de Sabadell, Institut Universitari Parc Taulí-UAB, Sabadell, CIBER de Enfermedades Respiratorias, CIBERES, Bunyola, Spain

10 Serviço de Medicina, Centro Hospitalar Universitario do Porto, Porto, Portugal

11 Emergency Medicine Department, University Hospital Hairmyres, Glasgow, Scotland

12 Pneumologia PROMISE, University of Palermo, Palermo, Italy

13 Respiratory Diseases Clinic, Policlinico di Modena, Modena, Italy

14 Respiratory Department, Hospital del Mar - IMIM, DCEXS-UPF, CIBERES, BRN, Barcelona, Spain

15 Critical Care Department, Hospital del Mar - IMIM, Barcelona, Spain

16 South Texas Veterans Health Care System and University of Texas Health San Antonio, San Antonio, USA 
CPGs appropriately recommend covering more than $90 \%$ of all the potential pathogens causing CAP, with the exception of patients enrolled from Germany, Pakistan, and Croatia. The 2019 ATS/IDSA CPGs appropriately recommend covering $93.6 \%$ of the cases compared with $90.3 \%$ of the ERS CPGs $(p<0.01)$. S. pneumoniae remains the most common pathogen in patients hospitalized with CAP. Multinational CPG recommendations for patients with CAP seem to appropriately cover the most common pathogens and should be strongly encouraged for the management of CAP patients.

Keywords Community-acquired pneumonia $\cdot$ Antimicrobial treatment $\cdot$ Guidelines $\cdot$ Streptococcus pneumoniae

\section{Introduction}

Community-acquired pneumonia (CAP) is a clinical and public health issue worldwide [1]. The Global Burden of Diseases, Injuries, and Risk Factors Study 2017 estimated that lower respiratory infections affected approximately 471.8 million people and caused 2.6 million deaths in 2017 [2].

The selection of an appropriate empirical antimicrobial therapy is crucial for a successful outcome [3]. National and international CAP guidelines provide specific recommendations based on site of care (intensive vs. non-intensive care unit) and pathogen-related risk factors, including those for Pseudomonas aeruginosa, methicillin-resistant Staphylococcus aureus (MRSA), and influenza viruses. However, it is unclear if those recommendations provide adequate antimicrobial coverage.

The aim of the present study was to describe the bacterial etiology of CAP in adults hospitalized in different settings, as well as to assess the appropriateness of the empirical treatment recommendations issued by clinical practice guidelines (CPGs) in relation to the bacteria detected in CAP patients.

\section{Materials and methods}

\section{Study design, setting, and participants}

We performed a secondary analysis of the Global Initiative for MRSA Pneumonia (GLIMP) study, an international, multicenter, point-prevalence study [4]. GLIMP was conducted across 222 hospitals in 54 countries over 4 days, with 1 day per month randomly selected during March, April, May, and June 2015. All consecutive adults ( $\geq 18$ years old) hospitalized for CAP at the participating centers were enrolled in the study. The following patients were excluded from the analysis: (i) immunosuppressed patients; (ii) patients not tested for bacterial agents of CAP within $24 \mathrm{~h}$ of admission; (iii) patients with a diagnosis of hospital-acquired or ventilator-associated pneumonia. Bacterial testing within $24 \mathrm{~h}$ of admission included the following: blood and respiratory cultures (e.g., sputum, pleural fluid, endotracheal aspirate, and bronchoalveolar lavage), pneumococcus urinary antigen, Legionella urinary antigen, serology for atypical pathogens, and lung biopsy. The
GLIMP coordinating center was located at the University of Texas Health, San Antonio, in San Antonio, TX, USA. The coordinating center received expedited project approval by the institutional review board (number HSC20150184E). The review board waived the need for receipt of informed consent due to the nature of the study. A detailed description of the GLIMP organization and methodology was previously published [4].

\section{Study outcomes}

The primary outcome of this study was the assessment of the appropriateness of the empirical antimicrobial treatment recommendations for CAP issued by CPGs, with particular emphasis on the appropriateness of country-specific CPG recommendations (see definition below).

\section{Study definitions}

CAP was defined by the presence of pulmonary infiltrates on thoracic imaging (chest radiograph, computerized tomography, or ultrasound) during the first $48 \mathrm{~h}$ of hospitalization and $\geq 1$ of the following criteria: new or increased cough with or without sputum production or with purulent respiratory secretions; fever (documented rectal or oral temperature $\geq 37.8^{\circ} \mathrm{C}$ ) or hypothermia (documented rectal or oral temperature $<36{ }^{\circ} \mathrm{C}$ ); and evidence of systemic inflammation, such as abnormal white blood cell count (leukocytosis [ $>10,000$ cells $/ \mu \mathrm{L}]$, leukopenia $[<4000$ cells $/ \mu \mathrm{L}]$, or bandemia $[>10 \%])$ and increased Creactive protein or procalcitonin concentrations above the local upper limit of normal. MRSA was defined according to the Clinical and Laboratory Standards Institute (CLSI) guidelines based on an oxacillin minimum inhibitory concentration $\geq$ $4 \mu \mathrm{g} / \mathrm{mL}$. Immunosuppression was defined by the presence of at least one among the following conditions: (i) AIDS, defined either as human immunodeficiency virus infection with CD4+ lymphocyte count $<200 / \mu \mathrm{L}$ or by the occurrence of an AIDSdefining condition; (ii) aplastic anemia; (iii) asplenia; (iv) hematological cancer (e.g., lymphoma, acute or chronic leukemia, or multiple myeloma); (v) chemotherapy during the last 3 months; (vi) neutropenia (neutrophil count $<500 / \mu \mathrm{L}$ ); (vii) administration of biological drugs (including trastuzumab and therapies for autoimmune diseases, e.g., anti-tumor necrosis 
factor $\alpha$, prescribed for $\geq 6$ months before hospital admission); (viii) lung transplantation; (ix) chronic steroid use (>10 mg/day of prednisone or equivalent prescribed for $\geq 3$ months before hospital admission); (x) lung cancer either with neutropenia or treated with chemotherapy; (xi) other solid tumors either with neutropenia or treated with chemotherapy; (xii) other immunodeficiencies (including congenital/genetic immunodepression and immunosuppressive therapy administered for hematological cancers/solid organ transplantations other than lungs) [5].

The following CAP CPGs were evaluated: the 2007 American Thoracic Society/Infectious Diseases Society of America (ATS/IDSA) guidelines [6], the 2019 ATS/IDSA guidelines [7], the European Respiratory Society (ERS) guidelines [8], the Spanish Society of Pneumology and Thoracic Surgery (SEPAR) guidelines [9], the Latin American Association of the Thorax (ALAT) guidelines [10], the Indian Chest Society and National College of Chest Physicians (ICS/NCCP) guidelines [11], the British Thoracic Society (BTS) guidelines [12], the guidelines issued by the German Respiratory Society, the Paul-Ehrlich-Society for Chemotherapy, the German Society for Infectious Diseases, the Competence Network CAPNETZ, the Austrian Respiratory Society, the Austrian Society for Infectious and Tropical Diseases and the Swiss Respiratory Society [13], the Pakistan Chest Society guidelines [14], the Portuguese Respiratory Society guidelines [15], and the Croatian guidelines [16] (Table 1).

The appropriateness of the recommendations issued by the CPGs was defined computing the concordance between the detected pathogens and the antibiotic(s) recommended by the CPGs. The therapy recommended by the CPGs relies on the clinical setting and the presence of risk factors for MRSA or $P$. aeruginosa. Treatment was deemed appropriate if effective against the diagnosed pathogen (Table 1).

\section{Statistical analysis}

Continuous variables are presented as medians with interquartile ranges (IQR). Categorical variables are summarized with absolute frequencies and percentages. Comparisons between groups were made with the chi-square or Fisher exact test, as appropriate. A two-sided $p$ value $<0.05$ was considered statistically significant. Statistical analyses were performed using the SPSS Statistics, version 24, software (IBM, Armonk, NY, US).

\section{Results}

Among the 2564 patients (57.9\% males; age, median, and IQR: 68; 53-80 years old) included in the analysis, 494 $(19.3 \%)$ were admitted in an ICU. The following bacterial tests were performed in the study population: blood cultures $(2110 ; 82.3 \%)$, sputum cultures $(1886 ; 73.6 \%)$, other respiratory cultures $(552 ; 21.5 \%)$, pneumococcal urinary antigen $(894 ; 34.9 \%)$, Legionella urinary antigen $(899 ; 35.1 \%)$, Mycoplasma pneumoniae serology (220; 8.6\%), Chlamydia pneumoniae serology (202; 7.9\%), Legionella pneumophila serology $(175 ; 6.8 \%)$, and lung biopsy $(7 ; 0.3 \%)$. At least one bacterial pathogen was identified as the causative agent of CAP in 906 (35.3\%) patients. Streptococcus pneumoniae was the most prevalent pathogen, accounting for $211(8.2 \%)$ cases. Pseudomonas aeruginosa and Klebsiella pneumoniae were the second and the third most prevalent pathogens, accounting for $105(4.1 \%)$ and $87(3.4 \%)$ cases, respectively. MRSA was responsible for $3.0 \%$ of CAP episodes globally, ranging from $1.2 \%$ of the cases in Portugal to $4.8 \%$ of the cases in USA and Argentina. After the stratification of nonICU vs. ICU patients, $S$. pneumoniae, $P$. aeruginosa, and $K$. pneumoniae continued to be the most prevalent etiologies (Table 2). A significantly higher proportion of CAP cases was caused by MRSA in the ICU in comparison with those managed in the non-ICU setting $(6.9 \%$ vs. $2.1 \%, p$ value $<0.01)$. Similarly, $P$. aeruginosa played a more relevant role in the ICU if compared with cases in the non-ICU setting $(6.7 \%$ vs. $3.5 \%$; $p$ value $<0.01)$.

Guideline recommendations were appropriate to cover potential pathogens in approximately $90 \%$ of the cases, both in ICU and in non-ICU patients, with the only exception of Germany, Pakistan, and Croatia, where a slightly inferior bacterial coverage was reported (Table 3 ). When the performance of country-specific CPGs was analyzed, a similar or slightly inferior bacterial coverage compared with the 2007 ATS/ IDSA, 2019 ATS/IDSA, and the ERS CPG recommendations was noted. Pakistan was the only country where nationspecific CPGs provided in the overall population and in the ICU population a higher empirical treatment coverage than the ATS/IDSA and ERS CPGs (Table 3).

The 2019 ATS/IDSA treatment recommendations appropriately covered a wider proportion of CAP cases than the ATS/IDSA 2007 and the ERS recommendations in the overall study population $(93.6 \%$ vs. $92.2 \%, p$ value $0.04 ; 93.6 \%$ vs. $90.3 \%, p$ value $<0.01)$. Similar results were achieved when the non-ICU population $(94.1 \%$ vs. $92.5 \%, p$ value 0.04 ; $94.1 \%$ vs. $90.5 \%, p$ value $<0.01)$ and the ICU population were evaluated $(91.9 \%$ vs. $90.9 \%, p$ value $0.57 ; 91.9 \%$ vs. $89.5 \%, p$ value 0.19 ) (Table 3 ).

While MRSA CAP was diagnosed in 34/494 (6.9\%) ICU cases, an anti MRSA empirical treatment was recommended by the 2007 and 2019 ATS/IDSA recommendations in 97/494 (19.6\%) and 124/494 (25.1\%) CAP ICU cases, respectively. Similarly, while $P$. aeruginosa CAP was diagnosed in 33/494 (6.7\%) ICU patients, an anti $P$. aeruginosa empirical treatment was suggested by the 2007 ATS/IDSA, the 2019 ATS/ IDSA, and the ERS recommendations in 163/494 (32.9\%), in $118 / 494(23.9 \%)$, and in 180/494 (36.4\%) CAP ICU cases, respectively (Figs. 1 and 2 ). 
Table 1 Main empirical treatment recommendations by national/international clinical practice guidelines for hospitalized CAP whether in the intensive care unit (ICU) or in non-ICU setting

\begin{tabular}{lll}
\hline CAP clinical practice guidelines & $\begin{array}{l}\text { Non-ICU CAP empirical } \\
\text { treatment recommendations }\end{array}$ & ICU CAP empirical treatment recommendations
\end{tabular}

ATS/IDSA guidelines 2007 [6] FQ or $\beta$-lactam plus macrolide.

ATS/IDSA guidelines 2019 [7]

ERS guidelines [8]

SEPAR guidelines [9]

\author{
ALAT guidelines [10] \\ ICS/NCCP guidelines [11]
}

BTS guidelines [12]

Germany guidelines [13] Pakistan Chest Society
guidelines [14]

Portuguese Respiratory Society guidelines [15]

Croatian guidelines [16]
FQ or $\beta$-lactam plus macrolide. If Pseudomonas aeruginosa risk factors, antipseudomonal $\beta$-lactam plus FQ or a macrolide. If risk factors for community-acquired Staphylococcus aureus, add vancomycin or linezolid.

$\beta$-lactam monotherapy or FQ or $\beta$-lactam plus macrolide.

FQ or $\beta$-lactam plus macrolide.

FQ or $\beta$-lactam plus macrolide.

$\beta$-lactam plus macrolide. FQ only if $\beta$-lactam allergy and no risk for tuberculosis.

$\beta$-lactam monotherapy or macrolide monotherapy, if low severity CAP. If moderate severity CAP, FQ or $\beta$-lactam plus macrolide.

FQ or $\beta$-lactam plus macrolide.

Macrolide monotherapy or FQ or $\beta$-lactam plus macrolide. If Pseudomonas aeruginosa risk factors, $\beta$-lactam plus either aminoglycoside or FQ or aminoglycoside and FQ.

FQ or $\beta$-lactam plus macrolide or $\beta$-lactam plus doxycycline.

$\beta$-lactam monotherapy or $\beta$-lactam plus macrolide. $\beta$-lactam plus either azithromycin or a respiratory FQ. If Pseudomonas aeruginosa risk factors, antipseudomonal $\beta$-lactam plus FQ or antipseudomonal $\beta$-lactam plus aminoglycoside and azithromycin or antipseudomonal $\beta$-lactam plus aminoglycoside and FQ. If risk factors for community-acquired Staphylococcus aureus, add vancomycin or linezolid.

$\beta$-lactam plus either a macrolide or a respiratory FQ. If Pseudomonas aeruginosa risk factors, antipseudomonal $\beta$-lactam plus FQ or a macrolide. If risk factors for community-acquired Staphylococcus aureus, add vancomycin or linezolid.

Non-antipseudomonal cephalosporin III plus either macrolide or FQ. If Pseudomonas aeruginosa risk factors, antipseudomonal $\beta$-lactam plus either FQ or aminoglycoside and macrolide.

$\beta$-lactam plus either azithromycin or FQ. If Pseudomonas aeruginosa risk factors, antipseudomonal $\beta$-lactam plus FQ. If risk factors for community-acquired methicillin-resistant Staphylococcus aureus, levofloxacin plus either vancomycin or linezolid.

Non-antipseudomonal $\beta$-lactam plus FQ. If Pseudomonas aeruginosa risk factors, antipseudomonal $\beta$-lactam plus $\mathrm{FQ}$.

Non-antipseudomonal $\beta$-lactam plus macrolide. If Pseudomonas aeruginosa risk factors, antipseudomonal $\beta$-lactam plus either macrolide or FQ. FQ can be used only if no risk factors for tuberculosis.

$\beta$-lactam plus macrolide.

$\beta$-lactam plus macrolide. If influenza season, add oseltamivir. If Pseudomonas aeruginosa risk factors, antipseudomonal $\beta$-lactam plus either FQ or aminoglycoside.

$\beta$-lactam plus either FQ or macrolide. If Pseudomonas aeruginosa risk factors, $\beta$-lactam plus either aminoglycoside or FQ or aminoglycoside and FQ. If MRSA risk factors, add vancomycin or linezolid.

$\beta$-lactam plus either FQ or macrolide. If Pseudomonas aeruginosa risk factors, either $\beta$-lactam plus FQ or $\beta$-lactam plus aminoglycoside plus FQ or macrolide.

Either $\beta$-lactam plus macrolide or FQ. If Pseudomonas aeruginosa risk factors, antipseudomonal $\beta$-lactam plus FQ.

ATS/IDSA, American Thoracic Society/Infectious Diseases Society of America; ERS, European Respiratory Society; SEPAR, Spanish Society of Pneumology and Thoracic Surgery; ALAT, Latin American Association of the Thorax; ICS/NCCP, Indian Chest Society and National College of Chest Physicians; BTS, British Thoracic Society; FQ, fluoroquinolone; $\beta$-lactam, beta-lactam; $C A P$, community-acquired pneumonia

\section{Discussion}

The present study showed that bacterial pathogens were detected in $35.3 \%$ of CAP patients tested for bacteria, with S. pneumoniae identified in $8.2 \%$ of the cases. National and international CPGs recommended an appropriate empirical treatment in the vast majority $(>90 \%)$ of the patients hospitalized with CAP, with national CPGs providing a similar or slightly inferior bacterial coverage compared with the ATS/IDSA and ERS CPGs. The 2019 ATS/IDSA tended to perform better than the 2007 ATS/IDSA and the ERS CPGs, both in the non-ICU and in the ICU setting. In general, CPGs suggested anti MRSA and anti $P$. aeruginosa treatments more frequently than needed. 


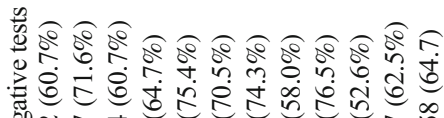

举

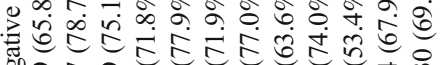

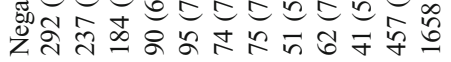

莺

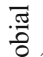

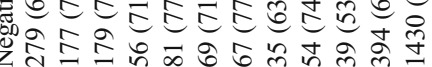

产

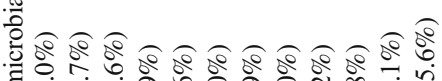

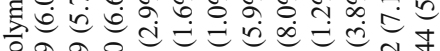

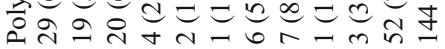

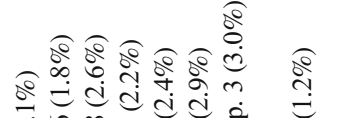

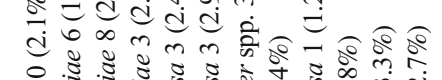

을.

ङ

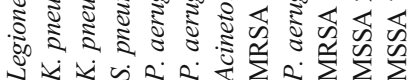

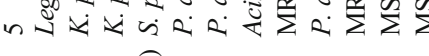

\& बे बे

वे

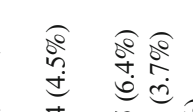

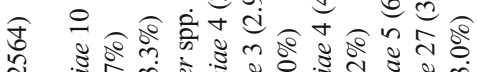

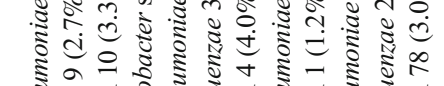

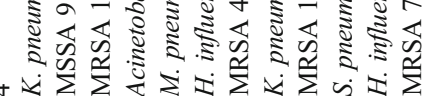

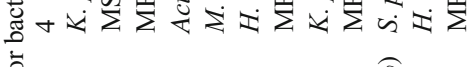

.]त्र

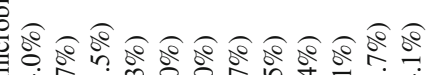

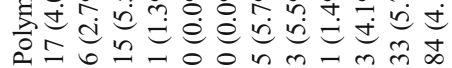

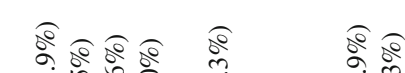

बind did d d d

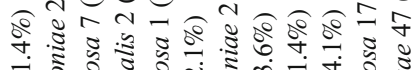

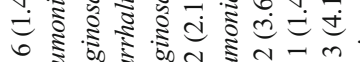

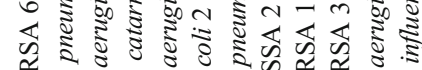

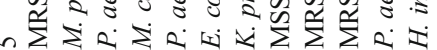

要古

苛

₹ के

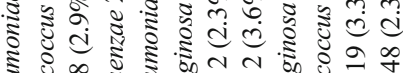

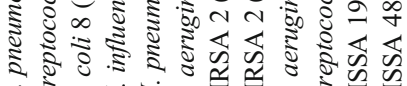

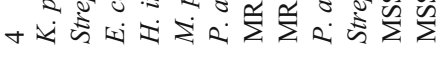

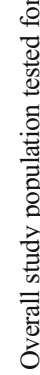

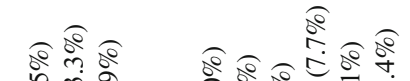

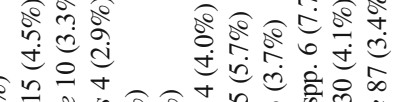

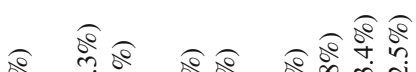

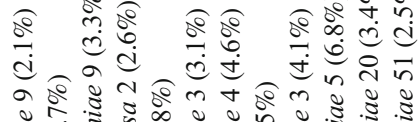

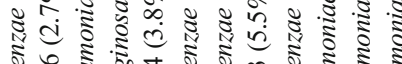

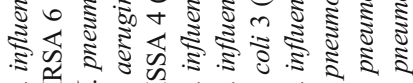

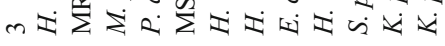

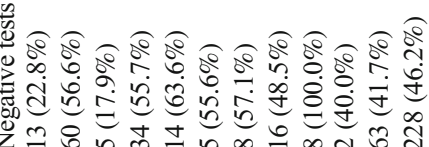

言

긍

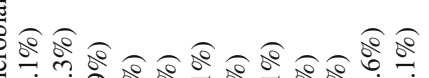

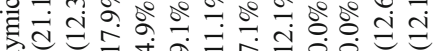

oaㅔ

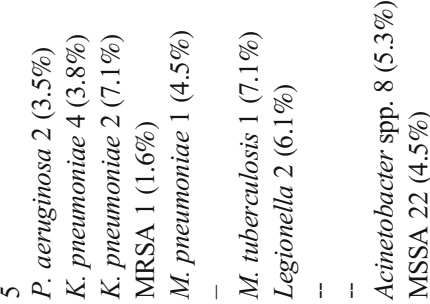

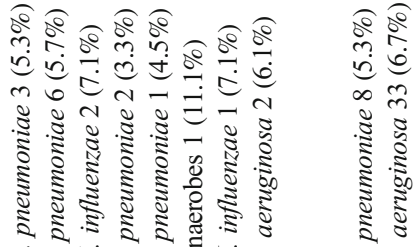

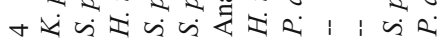

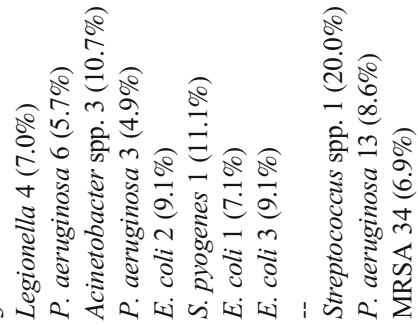

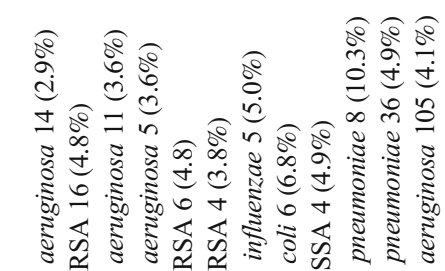

NR:

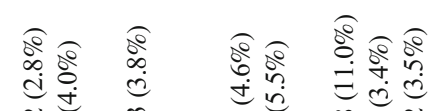

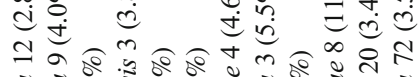

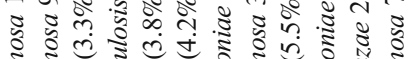

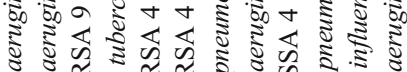

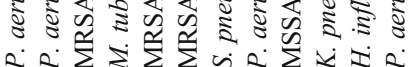

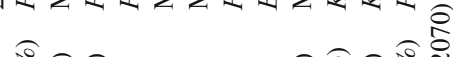

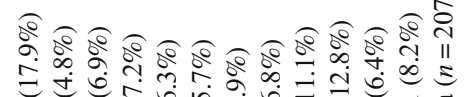

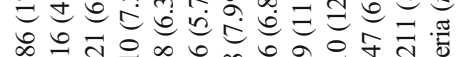

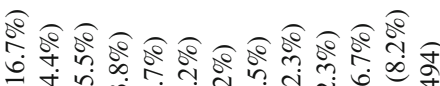

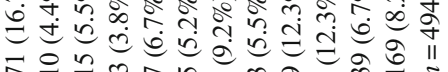

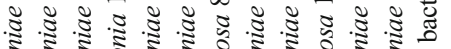

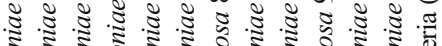

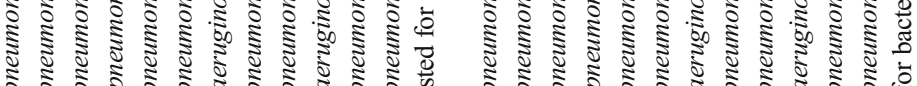

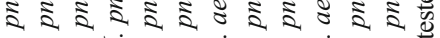

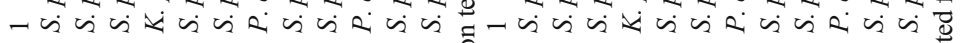

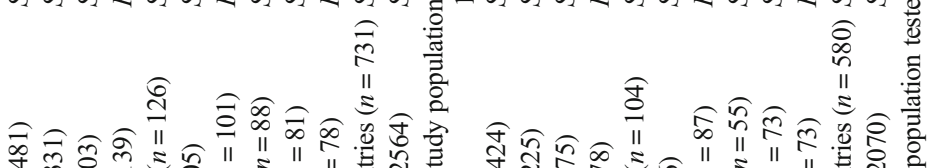

के

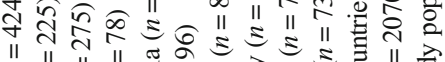

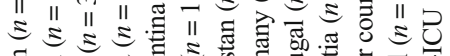

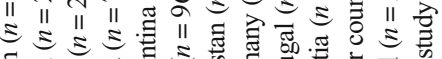

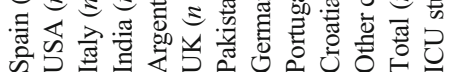

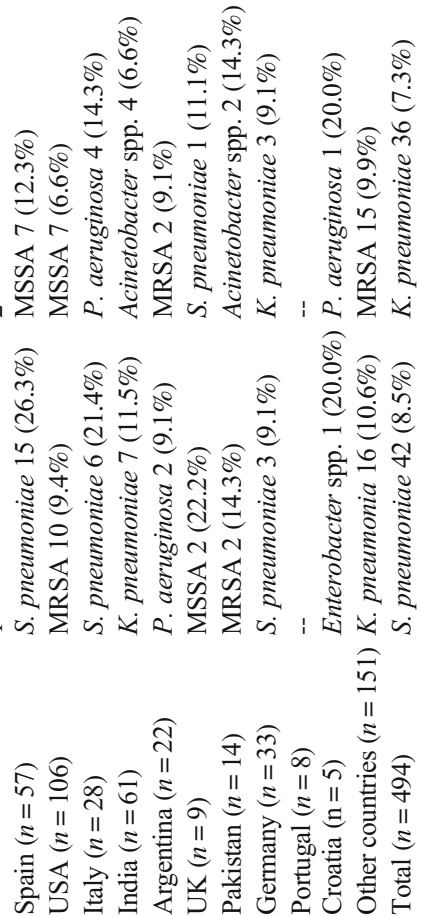




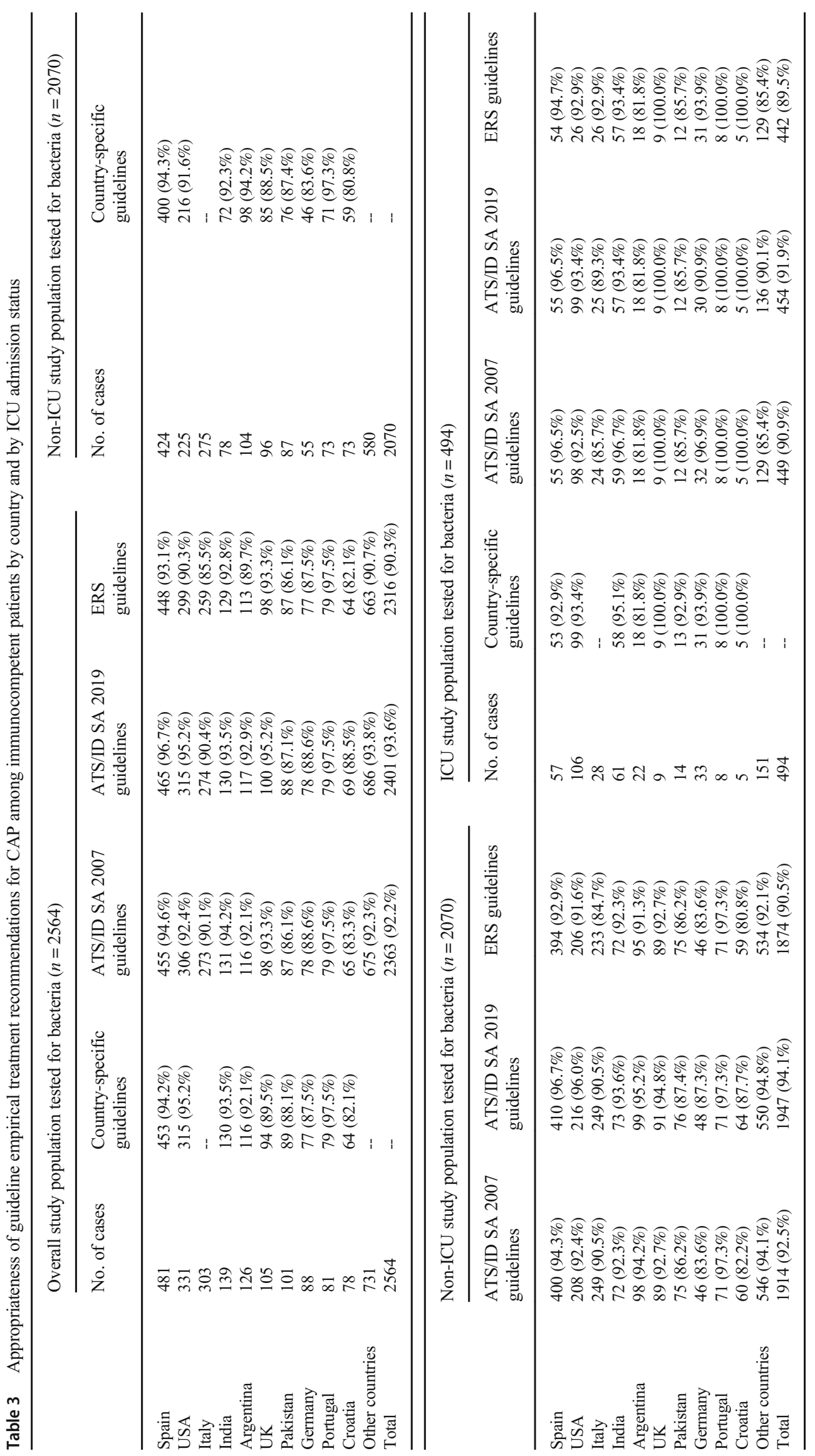


MRSA detection and anti MRSA empirical treatment recommendations for

CAP among ICU-admitted immunocompetent patients.

140

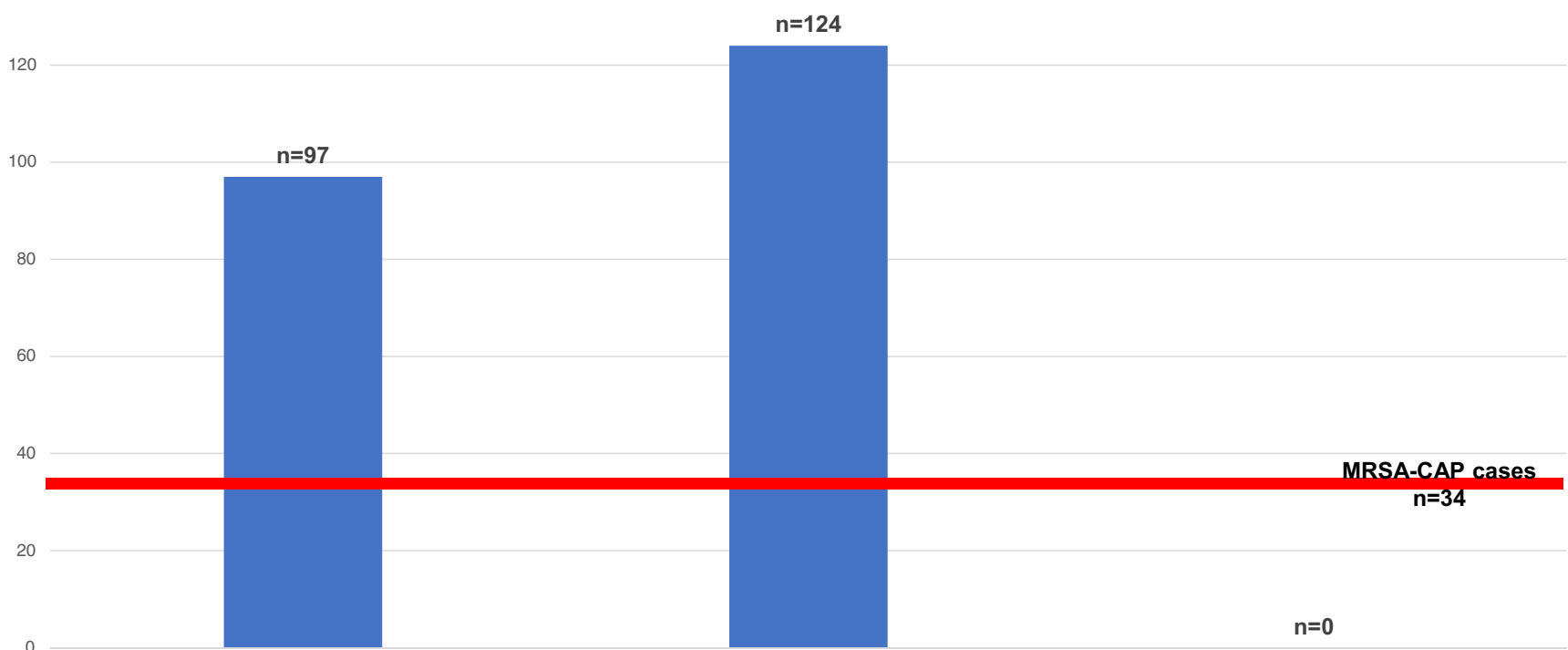

Anti-MRSA treatments by ATS/IDSA 2007 Anti-MRSA treatments by ATS/IDSA $2019 \quad$ Anti-MRSA treatments by ERS guidelines

Fig. 1 MRSA detection and anti MRSA empirical treatment recommendations for CAP among ICU-admitted immunocompetent patients

The diagnostic yield of bacterial testing that we observed in hospitalized CAP (35.3\% of the patients) is consistent with what is reported in other large studies, such as the EPIC study [17-20]. The EPIC study, which was a prospective, multicenter, population-based, active surveillance study conducted by the USA Centers for Disease Control and Prevention (CDC) between 2010 and 2012, enrolled 2259 adult patients hospitalized with CAP in the USA. The authors found a pathogen in only $37.7 \%$ of the cases [17-20]. On the contrary, in the Medicare administrative database, a pathogen was identified in $7.6 \%$ of the CAP cases [21]. When compared with previous studies, the novelty of the GLIMP approach lies in its point-prevalence design, international nature (222 centers in 54 countries in 6 continents), and the analysis of real-life

\section{$P$. aeruginosa detection and anti $P$. aeruginosa empirical treatment recommendations for CAP among ICU-admitted immunocompetent patients.}

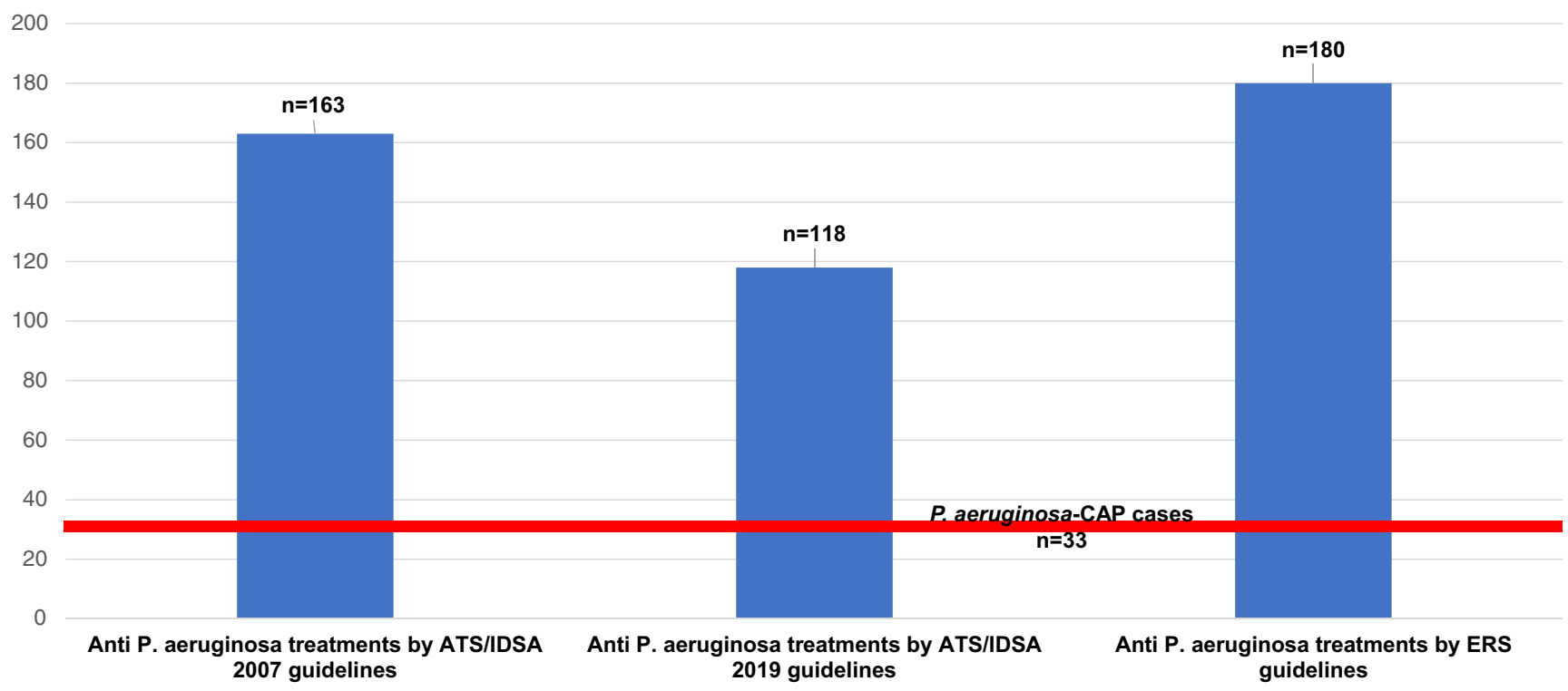

Fig. 2 Pseudomonas aeruginosa detection and anti P. aeruginosa empirical treatment recommendations for CAP among ICU-admitted immunocompetent patients 
data. Furthermore, the GLIMP approach differs from the Medicare database for its primary rather than administrative data collection. Several other factors may also account for the different results reported by the GLIMP study and the Medicare database. The review of the Medicare database was published in 2011 but was performed in 2009, 6 years before the GLIMP study was performed: the microbiological progress may partially justify this difference. Second, the Medicare review findings may reflect the implementation of the 2007 ATS/IDSA CAP CPGs, which discouraged any microbiological studies in most cases, and the issue of cost in the USA health care system [22]. Third, GLIMP data were derived from clinical sites, which are mostly tertiary care centers, whereas Medicare data might have included both tertiary and non-tertiary health care centers. Despite the variability of study-related characteristics, the persistently low pathogen detection yield highlights the suboptimal understanding of the dynamics of CAP etiology and the weak evidence supporting recommendations for empirical antimicrobial treatment. Therefore, studies implementing innovative pathogendiscovery approaches are urgently needed [22].

Our findings confirmed a substantial variability of CAP etiology depending on the geographic region and the clinical setting. S. pneumoniae was the most prevalent etiology overall both in the non-ICU and ICU settings [18, 23-25]. However, S. pneumoniae prevalence ranged from $17.9 \%$ CAP cases in Spain to 2.2\% CAP cases in India. This substantial variability in pneumococcal CAP cases may reflect the variability in pneumococcal vaccination rates and serotype circulation across regions [26, 27]. Mycobacterium tuberculosis was found to be an important agent of CAP, mainly in India and other Asian and African countries [28, 29].

MRSA was detected in 3.0\% of CAP cases worldwide [4]. Our secondary analysis highlighted a high prevalence of $S$. aureus CAP cases in the USA, at the point that $S$. aureus CAP was more frequent than $S$. pneumoniae CAP in the USA ( $7.5 \%$ vs. $4.8 \%$ of the CAP cases in the overall population). The unusual etiologic distribution of CAP in the USA may result from an epidemiological shift due to the broad pneumococcal vaccination coverage in the USA [26, 27]. This shift in microbiology patterns may have important implications in the antibiotic treatment guideline recommendations. Among $S$. aureus CAP in the USA, MRSA accounted for more than half of the cases. Similarly, Moran and collaborators detected MRSA in 14 out of 627 (2.4\%) of the patients hospitalized with CAP in the USA [30].

The significantly higher proportions of MRSA and $P$. aeruginosa CAP cases in the ICU compared with the non-ICU landscape suggests how clinical settings can influence the etiology of CAP. Frailty of patients harboring $P$. aeruginosa and severity of MRSA CAP may explain the higher frequency of $P$. aeruginosa and MRSA in the ICU [30-34]. These data strengthen the need for prompt microbiological testing in severe CAP cases, as those managed in the ICU. Furthermore, the not-infrequent occurrence of MRSA and $P$. aeruginosa CAP in the ICU calls for the selection of empirical antimicrobials based on the evaluation of pathogen-specific risk factors and for careful antimicrobial stewardship approaches in the ICU. Antimicrobial stewardship should allow a rapid deescalation of unnecessary antimicrobial treatments once microbiological tests are available and also an appropriate antimicrobial treatment duration.

Our study documented the appropriateness of empirical treatment guideline recommendations in more than $90 \%$ of the CAP cases evaluated, both in the non-ICU and in the ICU setting, reinforcing the invitation to implement guideline recommendations when treating patients with CAP.

With the sole exception of the Pakistan Chest Society CPGs, country-specific CPGs were inferior to ATS/IDSA and ERS CPGs in the appropriateness of empirical treatment recommendations in the overall study population and also in the non-ICU and in the ICU settings. Of note, when applied to the UK CAP patients, BTS CPGs appropriately covered $89.5 \%$ of the CAP cases, while ATS/IDSA and ERS CPGs covered more than $93 \%$ of the cases. Similarly, the performance of ERS CPGs was inferior to the performance of the 2019 ATS/IDSA CPGs, even when applied to European countries, such as Spain, Italy, UK, Germany, and Croatia. The suboptimal performance of country-specific CPGs in the epidemiological settings where they were meant to be applied suggests the presence of pitfalls in these CPGs. We could speculate that the following factors may have contributed to the low performance of country-specific CPGs: (i) BTS CPGs allow $\beta$-lactam monotherapy and macrolide monotherapy in the non-ICU setting, leaving uncovered atypical agents of CAP and several Gram-negative pathogens, respectively; (ii) anti MRSA and anti $P$. aeruginosa empirical treatments are not suggested in the ICU by the BTS CPGs; (iii) Croatian CPGs favor $\beta$-lactam monotherapy in the non-ICU setting, leaving uncovered atypical agents of CAP; (iv) differences in the identification of $P$. aeruginosa risk factors. Similarly, the difference between the 2019 ATS/IDSA and the ERS CPGs may be associated with the more restrictive use of anti MRSA coverage based on the ERS CPGs and with the more selective anti $P$. aeruginosa treatment indications based on the 2019 ATS/IDSA CPGs. In addition, the ERS recommendations attempt to provide a single set of recommendations for a large number of countries, which differ for geographic distribution, ecology, and health care system (see Electronic Supplementary Materials).

The slightly better performance of the 2019 ATS/IDSA compared with the 2007 ATS/IDSA CPGs may result from the more attentive selection of $P$. aeruginosa and MRSA risk factors and should be carefully re-evaluated by future studies in the upcoming years. 
Of note, we observed a significant difference between the frequency of anti MRSA treatments recommended by the 2007 and 2019 ATS/IDSA CPGs for ICU patients (97 and 124 empirical anti MRSA treatments recommended by the 2007 and 2019 ATS/IDSA CPGs, respectively) and the frequency of MRSA CAP diagnosed in the ICU (34 MRSA CAP). Similar results were found when anti $P$. aeruginosa treatment recommendations and $P$. aeruginosa CAP in ICU were evaluated. The high number of anti MRSA and anti $P$. aeruginosa empiric therapies recommended by the CPGs should prompt future studies to better define local risk factors for MRSA and P. aeruginosa, as suggested by the 2019 ATS/ IDSA CPGs. More stringent recommendations may reduce the use of unnecessary therapies, leading to a decrease in the rate of drug-related adverse events and of antimicrobial resistance.

This study has several limitations. First, this is a secondary analysis of an observational point-prevalence study that cannot yield causal relationships. Second, the external validity of this study is hampered by geographic and temporal constrains. Specifically, data were mainly retrieved from tertiary care centers. Furthermore, the GLIMP study enrolled patients during the period March-June 2015, in order to cover the end of the winter season in the Northern Hemisphere and the start of the winter season in the Southern Hemisphere. Studies carried out during different seasons or the whole year may yield different results. Finally, the results of the GLIMP study are indicative of the testing efforts and the etiology of CAP in 2015 and cannot be generalized to any time period before or after the year 2015. Third, complete radiological and anamnestic information were not included in the original GLIMP dataset, hampering our ability to detect conditions at increased risk for anti MRSA coverage (e.g., necrotizing pneumonia and previous influenza).

In conclusion, S. pneumoniae is the most prevalent bacterial pathogen in patients hospitalized with CAP. CPGs seem to appropriately recommend to cover the most prevalent pathogens in different settings and should be strongly encouraged when managing patients with CAP. Future studies should promote innovative microbiological testing for CAP and should address the gap between the CPG recommendations and the antibiotic prescription for patients hospitalized with CAP.

Acknowledgments We would like to thank the European Respiratory Society, the World Federation of Societies of Intensive and Critical Care Medicine, the American College of Chest Physicians, the Asociación Latinoamericana de Tórax (ALAT), and the Sociedad Argentina de Infectología (SAI) for their support of this project. We would like to thank the following study contributors (GLIMP Collaborators) for their valuable collaboration: Argentina: Patricia Karina Aruj, Dept of Internal Medicine, University Hospital Alfredo Lanari, Buenos Aires, Argentina; Silvia Attorri, Hospital Luis Lago Maggiore, Mendoza, Argentina; Enrique Barimboim, Hospital Central de Mendoza, Argentina; Juan Pablo Caeiro and María I. Garzón, Hospital Privado Universitario, Córdoba, Argentina; Victor Hugo Cambursano, V.H. Dr Cazaux A. Servicio de Neumologia,
Hospital Rawson, Córdoba, Argentina; Adrian Ceccato, Hospital Nacional Prof Alejandro Posadas, Argentina; Julio Chertcoff, Florencia Lascar, and Fernando Di Tulio, Critical Care Unit and Respiratory Medicine, Buenos Aires British Hospital, Buenos Aires, Argentina; Ariel Cordon Díaz, Hospital General Alvear, Ciudad, Mendoza, Argentina; Lautaro de Vedia, Respiratory Intensive Care Unit, Hospital Muñiz, Buenos Aires, Argentina; Maria Cristina Ganaha, Infectious Diseases Ward, Hospital Interzonal General de Agudos "Vicente Lopez y Planes" from General Rodriguez, Buenos Aires, Argentina; Sandra Lambert, Hospital El Cruce - Alta Complejidad en Red, Argentina; Gustavo Lopardo, Hospital Bernardo Houssay, Vicente López, Argentina; Carlos M. Luna, Pulmonary Medicine Division, Dept of Medicine, Hospital de Clínicas, Universidad de Buenos Aires, Argentina; Alessio Gerardo Malberti, Hospital Nuestra Señora del Carmen, Argentina; Nora Morcillo and Silvina Tartara, Hospital Zonal Especializado de Agudos y Crónicos Dr Antonio A. Cetrangolo, Argentina; Claudia Pensotti, Infectious Diseases and Infection Control Dept, Buenos Aires, Clinica Privada Monte Grande, Argentina; Betiana Pereyra, Hospital San Roque, Córdoba, Argentina; Pablo Gustavo Scapellato, Infectious Diseases Dept, Hospital D.F. Santojanni, Argentina; Juan Pablo Stagnaro, HZGA Mi Pueblo, Florencio Varela, Argentina. Australia: Sonali Shah, Dept of General Medicine, Austin Hospital, Heidelberg, Australia. Austria: Felix Lötsch and Florian Thalhammer, Division of Infectious Diseases and Tropical Medicine, Dept of Medicine I, Medical University of Vienna, Austria; Belgium: Kurt Anseeuw, ZNA Campus Stuivenberg, Antwerp, Belgium; Camille A. Francois, Anesthesia and Critical Care Dept, Erasme University Hospital, Brussels, Belgium; Eva Van Braeckel, Dept of Respiratory Medicine, Ghent University Hospital, Belgium; Jean Louis Vincent, Dept of Intensive Care, Erasme University Hospital, Université Libre de Bruxelles, Brussels, Belgium. Benin: Marcel Zannou Djimon, Jules Bashi, and Roger Dodo, Centre Hospitalier Universitaire HKM of Cotonou, Benin; Brazil: Simone Aranha Nouér, Federal University of Rio de Janeiro, Brazil; Bulgaria: Peter Chipev and Milena Encheva, Clinic of Pulmonary Diseases, Military Medical Academy, Sofia, Bulgaria; Darina Miteva, UMHAT "St Marina," Varna, Bulgaria; Diana Petkova, University Hospital Varna, Bulgaria; Cameroon: Adamou Dodo Balkissou, Yaounde Jamot Hospital, Yaounde, Cameroon; Eric Walter Pefura Yone, Département de Médecine Interne, University of Yaounde, Yaoundé, Cameroon; Bertrand Hugo Mbatchou Ngahane, Douala General Hospital, Douala, Cameroon; China: Ning Shen, Respiratory Medicine, Peking University Third Hospital, Beijing, China; Jin-fu Xu, Dept of Respiratory Medicine, Shanghai Pulmonary Hospital, Tongji University, China; Colombia: Carlos Andres Bustamante Rico and Ricardo Buitrago, Clinica Shaio, Bogota, Colombia; Fernando Jose Pereira Paternina, Las Americas Clinic, Medellin, Colombia; Congo: Jean-Marie Kayembe Ntumba, Cliniques Universitaires de Kinshasa, DR Congo; Croatia: Vesna Vladic Carevic, Interne Medicine, Dubrovnik, Croatia; Marko Jakopovic, Medical School, University of Zagreb, Dept for Respiratory Diseases Jordanovac, University Hospital Centre Zagreb, Zagreb, Croatia; Mateja Jankovic, University Hospital Center Zagreb, Dept for Respiratory Diseases, Zagreb, Croatia; Zinka Matkovic, University Hospital Dubrava, Zagreb, Croatia; Ivan Mitrecic, Karlovac General Hospital, Karlovac, Croatia; Denmark: Marie-Laure Bouchy Jacobsson, Emergency Dept, Nordsjællands Hospital, Hillerød, Denmark; Anette Bro Christensen, Dept of Anaethesiology, Viborg Region Hospital, Denmark; Uffe Christian Heitmann Bødtger, Dept of Pulmonology, Naestved Hospital, Denmark; Christian Niels Meyer, Dept of Internal Medicine, Roskilde Hospital, Copenhagen University Hospital, Roskilde, Denmark; Andreas Vestergaard Jensen, Gertrud Baunbæk-Knudsen, Pelle Trier Petersen and Stine Andersen, Dept of Lung and Infectious Diseases, Nordsjællands Hospital, Hillerød, Denmark; Egypt: Ibrahim El-Said Abd El-Wahhab, Thoracic Medicine, Faculty of Medicine, Mansoura University, Egypt; Nesreen Elsayed Morsy, Pulmonary, Critical Care and Sleep Medicine, Faculty of Medicine, Mansoura University, Mansoura, Egypt; Hanaa Shafiek, 
Chest Diseases Dept, Faculty of Medicine, Alexandria University, Egypt; Eman Sobh, Chest Diseases Dept, Al-Azhar University, Cairo, Egypt; Ethiopia: Kedir Abdella Abdulsemed, Dept of Medical Laboratory Science and Pathology, College of Health Sciences, Mycobacteriology Research Centre, Institute of Biotechnology Research, Jimma University, Jimma, Ethiopia; France: Fabrice Bertrand, Critical Care Unit, Robert Ballanger Hospital, Aulnay sous Bois, France; Christian Brun-Buisson, Univ Hospital Henri Mondor, 94000 Créteil, France; Etienne de Montmollin, Intensive Care Unit, Hôpital Delafontaine, Centre Hospitalier de Saint-Denis, Saint-Denis, France; Muriel Fartoukh, Unité de Réanimation Médico-Chirurgicale, Pôle Thorax Voies Aériennes, Hôpital Tenon, Groupe Hospitalier Est Parisien, France; Jonathan Messika, Publique-Hôpital de Paris, Service de Réanimation Médico-Chirurgicale, Hôpital Louis Mourier, Colombes, France, and Université Paris Diderot, IAME, UMR 1137, Sorbonne Paris Cité, Paris, France; Pierre Tattevin, Infectious Diseases and ICU, Pontchaillou University Hospital, Rennes, France; Abdo Khoury, Dept of Emergency Medicine and Critical Care, University of Franche Comté, Medical Center, France; Gambia: Bernard Ebruke, Medical Research Council Unit, Gambia. Germany: Michael Dreher, Dept of Cardiology, Pneumology, Vascular Medicine and Intensive Care Medicine, University Hospital Aachen, Aachen, Germany; Martin Kolditz, Division of Pulmonology, Medical Dept I, University Hospital Carl Gustav Carus, Technische Universität Dresden, Germany; Matthias Meisinger, Klinikum Niederlausitz GmbH, Klinik für Innere Medizin und Intensivmedizin, Senftenberg, Germany; Mathias W. Pletz and Stefan Hagel, Center for Infectious Diseases and Infection Control, Jena University Hospital, Germany; Jan Rupp, Dept of Molecular and Infectious Diseases, University of Lübeck, Lübeck, Germany; Tom Schaberg, Zentrum für Pneumologie, Agaplesion Diakonieklinikum Rotenburg, Germany; Marc Spielmanns, Internal Medicine Dept, Pulmonary Rehabilitation and Dept of Health, School of Medicine, University Witten-Herdecke, St Remigius-Hospital, Leverkusen, Germany; Petra Creutz and Norton Suttorp, Dept of Infectious Disease and Respiratory Medicine, Charité - University Medicine, Berlin, Germany; Ghana: Beatrice Siaw-Lartey, Komfo-Anokye Teaching Hospital, Kumasi, Ghana; Greece: Katerina Dimakou, 5th Respiratory Medicine Dept, "SOTIRIA" Chest Hospital, Athens, Greece; Dimosthenis Papapetrou, Medical Group of Athens (Paleo Faliro Clinic), Athens, Greece; Evdoxia Tsigou and Dimitrios Ampazis, Agioi Anargiroi Hospital, Kifissia, Athens, Greece; Evangelos Kaimakamis, Intensive Care Unit, "G. Papanikolaou" General Hospital of Thessaloniki, Greece; Mina Gaga, 7th Respiratory Medicine Dept and Asthma Center, Athens Chest Hospital, Greece; India: Mohit Bhatia, S.S. Hospital IMS BHU Varanasi, India; Raja Dhar, Fortis Hospitals, Kolkata, India; George D'Souza, Dept of Pulmonary Medicine, St John's Medical College Hospital, Bangalore, India; Rajiv Garg, Dept of Respiratory Medicine, King George's Medical University UP, Lucknow, India; Parvaiz A. Koul, Dept of Internal and Pulmonary Medicine, SheriKashmir Institute of Medical Sciences, Srinagar, India; P.A. Mahesh and B.S. Jayaraj, Dept of Pulmonary Medicine, JSS Medical College, JSS University, Mysore, India; Kiran Vishnu Narayan, Pulmonary Medicine, Government Medical College Kozhikode, Kerala, India; Hirennappa B. Udnur and Shashi Bhaskara Krishnamurthy, Columbia Asia Hospital, Hebbal, Bengaluru, Karnataka, India; Surya Kant, Dept of Respiratory Medicine, King George's Medical University, Chowk, Lucknow, Uttar Pradesh, India; Rajesh Swarnakar, Getwell Hospital and Research Institute, Dhantoli, Nagpur, India; Sneha Limaye and Sundeep Salvi, on behalf of the Respiratory Research Network of India (RRNI) from the Chest Research Foundation in Pune, India; Iran: Keihan Golshani, Isfahan University of Medical Sciences; Iran; Ireland: Vera M. Keatings, Letterkenny General Hospital, Co. Donegal, Ireland; Ignacio Martin-Loeches, Multidisciplinary Intensive Care Research Organization (MICRO), St James's University Hospital, Trinity Centre for Health Sciences Dublin, Ireland; Israel: Yasmin Maor, Infectious Disease Unit, Affiliated to Tel Aviv University, Wolfson Medical
Center, Holon, Israel; Jacob Strahilevitz, Dept of Clinical Microbiology and Infectious Diseases, Hadassah-Hebrew University, Jerusalem, Israel; Italy: Salvatore Battaglia, University of Palermo, Pneumologia DiBiMIS, Palermo, Italy; Maria Carrabba, Internal Medicine Dept, Fondazione IRCCS Ca' Granda Ospedale Maggiore Policlinico, Milan, Italy; Piero Ceriana, Pulmonary Rehabilitation, IRCCS Fondazione Maugeri, Pavia, Italy; Marco Confalonieri, Dept of Pulmunology, University Hospital, Trieste, Italy; Antonella d'Arminio Monforte, Dept of Health Sciences, Clinic of Infectious Disease, San Paolo Hospital, University of Milan, Italy; Bruno Del Prato, Interventional Pneumology, Hospital Antonio Cardarelli, Naples, Italy; Marino De Rosa, UOC Pneumologia P.O. San Filippo Neri ASL RM E Roma, Italy; Riccardo Fantini, Respiratory Diseases Clinic, Policlinico di Modena, Modena, Italy; Giuseppe Fiorentino, UOC Fisiopatologia e Riabilitazione Respiratoria AO Ospedali dei Colli PO Monaldi, Italy; Maria Antonia Gammino, Pulmonary Medicine Unit, San Martino Hospital, ASL 5 Oristano, Sardegna, Italy; Francesco Menzella, Dept of Cardiac-Thoracic-Vascular and Intensive Care Medicine, Pneumology Unit, IRCCS-Arcispedale Santa Maria Nuova, Reggio Emilia, Italy; Giuseppe Milani, Azienda Ospedaliera Sant Anna di Como, Presidio Ospedale S. Anna Nuovo, Unità Operativa di Pneumologia, Como, Italy; Stefano Nava, Alma Mater University of Bologna, DIMES, Respiratory and Critical Care Unit Sant'Orsola Malpighi Hospital, Italy; Gerardo Palmiero, Respiratory Unit, Versilia Hospital, Azienda USL 12 Viareggio, Lido di Camaiore, Lucca, Italy; Roberta Petrino and Barbra Gabrielli, Emergency Medicine Unit, S. Andrea Hospital, Vercelli, Italy; Paolo Rossi, Internal Medicine Dept, Azienda Ospedaliero-Universitaria S. Maria della Misericordia, Udine, Italy; Claudio Sorino, Pulmonology Unit, A.O. Sant Anna di Como, Italy; Gundi Steinhilber, Spedali Civili Brescia, U.O. Pneumologia e Fisiopatologia Respiratoria, Brescia, Italy; Alessandro Zanforlin, ULSS 18 Rovigo, Ospedale San Luca, Trecenta, Italy; Fabio Franzetti, Manuela Carugati, Manuela Morosi and Elisa Monge, Dept of Biomedical and Clinical Sciences, Division of Infectious Diseases, Luigi Sacco Hospital, Università degli Studi di Milano, Milan, Italy; Mauro Carone, Fondazione Salvatore Maugeri, IRCCS, Cassano Murge, Italy; Vincenzo Patella, Allergology and Clinical Immunology Unit, Dept of Medical Sciences, Battipaglia Hospital, Battipaglia, Salerno, Italy; Simone Scarlata, Geriatrics, Unit of Respiratory Pathophysiology and Thoracic Endoscopy, Campus Bio Medico University and Teaching Hospital, Rome, Italy; Andrea Comel, UO Pneumologia, Ospedale Pederzoli, Peschiera del Garda, Italy; Japan: Kiyoyasu Kurahashi, Yokohama City University Medical Center, Japan; Lebanon: Zeina Aoun Bacha, Medicine School, St Joseph University, Beyrouth, Lebanon; Mexico: Daniel Barajas Ugalde, National Institute of Respiratory Diseases, Mexico; Omar Ceballos Zuñiga, Hospital General de Mexicali, Mexicali, Baja California, Mexico; José F. Villegas, Hospital Universitario, Monterrey, Mexico; Montenegro: Milic Medenica, Hospital for Lung Diseases - Brezovik, Niksic, Montenegro; The Netherlands: E.M.W. van de Garde, Dept Clinical Pharmacy, St Antonius Hospital, Utrecht/Nieuwegein, The Netherlands; Nepal: Deebya Raj Mihsra, Internal Medicine, BP Koirala Institute of Health Sciences, Nepal; Poojan Shrestha, Oxford University Clinical Research Unit, Patan Hospital, Nepal; New Zealand: Elliott Ridgeon, Medical Research Institute of New Zealand; Nigeria: Babatunde Ishola Awokola, Dept of Family Medicine and Primary Care, Lily Hospitals Limited, Warri, Nigeria; Ogonna N.O. Nwankwo, University of Calabar Teaching Hospital, Calabar, Nigeria; Adefuye Bolanle Olufunlola, Olabisi Onabanjo University Teaching Hospital, Sagamu, Ogun State, Nigeria; Segaolu Olumide, Dept of Medicine (Pulmonary Unit), University College Hospital, Ibadan, Nigeria; Kingsley N. Ukwaja, Dept of Medicine, Federal Teaching Hospital Abakaliki, Ebonyi State, Nigeria; Pakistan: Muhammad Irfan, Section of Pulmonary and Critical Care Medicine, Dept of Medicine, Aga Khan University, Karachi, Pakistan; Poland: Lukasz Minarowski, Dept of Lung Diseases and Tuberculosis, Medical University of Bialystok, Poland; Skoczyński Szymon, Dept of Pneumology, School of Medicine in Katowice, Medical University of 
Silesia, Katowice, Institute of Occupational Medicine and Environmental Health, Sosnowiec, Poland; Portugal: Felipe Froes, Hospital Pulido Valente - CHLN, Lisbon, Portugal; Pedro Leuschner, Centro Hospitalar do Porto, Porto, Portugal; Mariana Meireles, Cláudia Ferrão, Pedro Leuschner and João Neves, Serviço de Medicina, Centro Hospitalar do Porto, Largo Prof Abel Salazar, Porto, Portugal; Sofia B Ravara, Faculty of Health Sciences, University of Beira Interior; Cova da Beira Hospital Center, Covilhã, Portugal; Republic of Moldova: Victoria Brocovschii, Dept of Pneumology and Allergology, State University of Medicine and Pharmacy "Nicolae Testemitanu" Republic of Moldova; Chesov Ion, Clinic of Anesthesia and Intensive Care "Valeriu Ghrerg," Institute of Emergency Medicine, State University of Medicine and Pharmacy "Nicolae Testemitanu," Chisinau, Republic of Moldova; Doina Rusu, SMFU "N. Testemitanu," Chisinau, Republic of Moldova; Cristina Toma, Dept of Pneumology and Allergology, State University of Medicine and Pharmacy "Nicolae Testemitanu," Chisinau, Republic of Moldova; Romania: Daniela Chirita, Hospital Sfantul Stefan, Bucharest, Romania; Carmen Mihaela Dorobat, Universitatea de Medicină și Farmacie "Gr. T. Popa" Iaşi Facultatea de Medicină Stomatologică, Spitalul Clinic de Boli Infecțioase "Sfầnta Parascheva," Iași, Romania; Russia: Alexei Birkun, Dept of Anesthesiology, Critical Care and Emergency Medicine, Medical Academy named after S.I. Georgievsky, Russian Federation; Anna Kaluzhenina, Volgograd State Medical University, Russia; Saudi Arabia: Abdullah Almotairi, King Fahad medical City (KFMC), Riyadh, KSA; Zakeya Abdulbaqi Ali Bukhary, College of Medicine, Taibah University, Medina, KSA; Jameela Edathodu, Al Faisal University, King Faisal Specialist Hospital, Riyadh, KSA; Amal Fathy, Pulmonary and Respiratory Critical Care Medicine, Mansoura University Egypt, Affiliate at Taibah University, KSA; Abdullah Mushira Abdulaziz Enani and Nazik Eltayeb Mohamed, Infectious Diseases Section, Medical Specialties Dept, King Fahad Medical City, Riyadh, KSA; Jawed Ulhadi Memon, Pulmonology Division, Dept of Internal Medicine, King Fahad Hospital, Hofuf, Al Ahasa, KSA; Abdelhaleem Bella, Dammam University-Saudi Arabia and King Fahad Hospital, KSA; Serbia: Nada Bogdanović, Pulmonary Dept of KHC Dr Dragiša Mišović, Belgrade, Serbia; Branislava Milenkovic, Clinic for Pulmonary Diseases, Clinical Centre of Serbia, Faculty of Medicine, University of Belgrade, Belgrade, Serbia; Dragica Pesut, University of Belgrade School of Medicine, Teaching Hospital of Pulmonology, Clinical Centre of Serbia, Belgrade, Serbia; South Africa: Charles Feldman, Division of Pulmonology, Dept of Internal Medicine, Charlotte Maxeke Johannesburg Academic Hospital, Faculty of Health Sciences, University of the Witwatersrand, Johannesburg, South Africa; South Korea: Ho Kee Yum, Inje Univ Seoul Paik Hospital, South Korea; Spain: Luis Borderìas, Respiratory and Sleep Unit, Hospital San Jorge, Huesca, Spain; Noel Manuel Bordon Garcia, Barcelona Policlínic and Moises Broggi Hospital at Sant Joan Despí, Spain; Hugo Cabello Alarcón, Sant Hospital Seu de Urgell, Catalonia, Spain; Catia Cilloniz and Antoni Torres, Dept of Pneumology, Institut Clinic del Tórax, Hospital Clinic of Barcelona, Institut d'Investigacions Biomèdiques August Pi i Sunyer (IDIBAPS), University of Barcelona, Spain; Vicens Diaz-Brito and Xavier Casas, Infectious Diseases Unit and Pneumology Service, Parc Sanitari Sant Joan de Deu, Sant Boi, Barcelona, Spain; Alicia Encabo González, Hospital Complex of Pontevedra, Spain; Maria Luisa Fernández-Almira, Medicina Interna, Hospital Universitario Central de Asturias, Spain; Miguel Gallego, Dept of Respiratory Medicine, Hospital de Sabadell, Institut Universitari Parc Taulí-UAB, Sabadell, CIBER de Enfermedades Respiratorias, CIBERES, Bunyola, Spain; Inmaculada Gaspar-GarcÍa, Dept of Respiratory Medicine, Hospital Costa del Sol, Marbella, Málaga, Spain; Juan González del Castillo, Emergency Dept, Hospital Universitario Clínico San Carlos, Madrid, Spain; Patricia Javaloyes Victoria, Hospital General Universitario de Alicante, Alicante, Spain; Elena Laserna Martínez, Hospital Mollet, Barcelona, Spain; Rosa Malo de Molina, University Hospital Puerta de Hierro Majadahonda, Madrid; Pedro J. Marcos, Servicio de Neumología, Complejo Hospitalario Universitario de A Coruña (CHUAC), INIBIC,
Sergas, Universidade de A Coruña (UDC), Spain; Rosario Menéndez, Pneumology Service, University and Polytechnic Hospital La Fe, Valencia, Spain; Ana Pando-Sandoval, Hospital Universitario Central de Asturias, Area de Gestion Clinica de Pulmon, Servicio de Neumologia, Oviedo, Spain; Cristina Prat Aymerich, Alicia Lacoma de la Torre and Ignasi García-Olivé, Microbiology Dept and Pneumology Dept, Hospital Universitari Germans Trias i Pujol, Institut d'Investigació Germans Trias i Pujol, Badalona, Universitat Autònoma de Barcelona, CIBER Enfermedades Respiratorias (CIBERES), Instituto de Salud Carlos III, Spain; Jordi Rello and Silvia Moyano, Critical Care Dept, Hospital Vall d'Hebron, Barcelona, Spain; Francisco Sanz, Servicio de Neumología, Consorci Hospital General Universitari de Valencia, Valencia, Spain; Oriol Sibila and Ana Rodrigo-Troyano, Servei de Pneumologia, Hospital de la Santa Creu i Sant Pau, IIB-Sant Pau, Barcelona, Spain; Jordi Solé-Violán, Hospital Universitario de Gran Canaria Dr Negrín, Las Palmas de Gran Canaria, Spain; Ane Uranga, Pulmology Dept, Hospital of Galdakao-Usansolo, Spain; Job F.M. van Boven, Hospital Universitari Son Espases, Palma de Mallorca, Spain; Ester Vendrell Torra and Jordi Almirall Pujol, Intensive Care Medicine, Hospital de Mataró, Spain; Togo: Arnauld Attannon Fiogbe, Pulmonology and Infectious Diseases Service/University Hospital of Sylvanus Olympio, Lomé, Togo; Tunisia: Ferdaous Yangui, Dept of Pneumology, Hospital of Internal Forces Security (IFS), Marsa, Tunis, Tunisia; Turkey: Semra Bilaceroglu, Izmir Dr Suat Seren Training and Research Hospital for Thoracic Medicine and Surgery, Izmir, Turkey; Levent Dalar, Pulmonary Medicine, Istanbul Bilim University, Istanbul, Turkey; Ufuk Yilmaz, Suat Seren Chest Disease and Surgery Training and Research Hospital, İzmir, Turkey; Ukraine: Artemii Bogomolov, Vinnitsa National Pirogov Memorial Medical University, Vinnitsa Regional Antituberculosis Hospital, Vinnitsa, Ukraine; United Arab Emirates: Naheed Elahi, Dubai Hospital, UAE; UK: Devesh J. Dhasmana, Victoria Hospital, Kirkcaldy, NHS Fife, UK; Andrew Feneley, Rhiannon Ions, Julie Skeemer and Gerrit Woltmann, University Hospitals of Leicester NHS Trust and University of Leicester, Leicester, UK; Carole Hancock, Royal Respiratory Research Team, Royal Liverpool University Hospital, Liverpool, UK; Adam T. Hill, Royal Infirmary and University of Edinburgh, UK; Banu Rudran, The Royal London Hospital, Barts Health Trust, London, UK; Silvia Ruiz-Buitrago and Marion Campbell, Hairmyres Hospital, Eaglesham Road, East Kilbride, UK; Paul Whitaker, Dept of Respiratory Medicine, St James's Hospital, Leeds, UK; Alexander Youzguin, Southport and Ormskirk Hospitals NHS Trust, UK; Anika Singanayagam, Imperial College Healthcare NHS Trust, London, UK; USA: Karen S. Allen, University of Oklahoma Health Sciences Center, Oklahoma City, OK, USA; Veronica Brito, Texas A\&M Health Science Center, Division of Pulmonary, Critical Care and Sleep Medicine, Baylor Scott \& White Health, TX, USA; Jessica Dietz, Fargo VA Health Care System, Fargo, ND, USA; Claire E. Dysart and Susan M. Kellie, Clement J. Zablocki VA Medical Center, Milwaukee, WI, USA, Division of Infectious Diseases, University of New Mexico School of Medicine, Raymond G. Murphy VA Medical Center, Albuquerque, NM, USA; Ricardo A. Franco-Sadud and Garnet Meier, Division of Hospital Medicine, Cook County Hospital, Chicago, IL, USA; Thomas L. Holland and Stephen P. Bergin, Dept of Medicine, Duke University Medical Center and School of Medicine, Duke Clinical Research Institute, Durham, NC, USA; Fayez Kheir, Dept of Pulmonary Diseases, Critical Care and Environmental Medicine, Tulane University Health Sciences Center, New Orleans, LA, USA; Mark Landmeier, Division of Pulmonary and Critical Care Medicine, Northwestern Memorial Hospital, Chicago, IL, USA; Manuel Lois, John Peter Smith Hospital, Fort Worth, TX, USA; Girish B. Nair, Interstitial Lung Disease Program and Pulmonary Rehabilitation, SUNY Stony Brook Winthrop University Hospital, Mineola, NY, USA; Hemali Patel, Dept of Medicine, Division of General Internal Medicine, Hospital Medicine Group, University of Colorado, CO, USA; Katherine Reyes, Henry Ford Hospital, Detroit, IL, USA; William Rodriguez-Cintron, Pulmonary/Critical Care Medicine, VA Caribbean Healthcare System, 
USA; Shigeki Saito, Tulane University, New Orleans, LA, USA; Nilam J. Soni, Julio Noda, Cecilia I. Hinojosa, Stephanie M. Levine, Luis F. Angel, Luis F. Reyes and Antonio Anzueto, Divisions of Hospital Medicine and Pulmonary/Critical Care Medicine, South Texas Veterans Health Care System, University of Texas Health Science Center San Antonio, San Antonio, TX, USA; K. Scott Whitlow, John Hipskind, Kunal Sukhija and Vicken Totten, Kaweah Delta Health Care District, Dept of Emergency Medicine, Visalia, CA, USA; Richard G. Wunderink and Ray D. Shah, Northwestern University Feinberg School of Medicine, Chicago, IL, USA; Zambia: Kondwelani John Mateyo, Dept of Internal Medicine, University Teaching Hospital, Lusaka, Zambia. Other investigators: Lorena Noriega, Ezequiel Alvarado, Mohamed Aman, and Lucía Labra.

Authors' contribution Conceptualization, MC, SA, MIR; methodology, MC, SA, GS, MIR; formal analysis, MC, GS; writing - original draft preparation, MC, SA, GS, MIR; writing - review and editing, RM, ME, MG, PL, SRB., SB, RF, SPG, JMC; supervision, AG, FB, and MIR. Guarantor: Marcos I. Restrepo, MD, MSc, PhD; takes full responsibility for the content of the manuscript, including the data and analysis.

Data availability The dataset analyzed during the current study is available from the corresponding author on reasonable request.

\section{Compliance with ethical standards}

Conflict of interest MC, AS, GS, RM, ME, MG, PL, SRB, SB, RF, SPG, JMC, and MIR have no conflict of interest to declare. FB reports recent grants and personal fees from AstraZeneca, Bayer, Chiesi, Grifols, GSK, Guidotti, Insmed, Menarini, Novartis, Pfizer, and Zambon outside the present manuscript. AG reports recent grants and personal fees from Abbvie, Gilead, Janssen, MSD, Pfizer, ViiV, Menarini, and Angelini outside the present manuscript.

Ethical approval and informed consent The GLIMP coordinating center was located at the University of Texas Health, San Antonio, in San Antonio, TX, USA. The coordinating center received expedited project approval by the institutional review board (number HSC20150184E). The review board waived the need for receipt of informed consent due to the nature of the study. A detailed description of the GLIMP organization and methodology was previously published [4].

Disclaimer The content of this manuscript is solely the responsibility of the authors and does not necessarily represent the official views of the Department of Veterans Affairs.

\section{References}

1. Aliberti S, Dela Cruz CS, Sotgiu G, Restrepo MI (2019) Pneumonia is a neglected problem: it is now time to act. Lancet Respir 7:10-11

2. GBD 2017 Causes of Death Collaborators (2018) Global, regional, and national age-sex-specific mortality for 282 causes of death in 195 countries and territories, 1980-2017: a systematic analysis for the Global Burden of Disease Study 2017. Lancet 392:1736-1788

3. Murayama T, Fujisawa T, Ishida T, Ito A, Oyamada Y, Fujimoto K, Yoshida M, Maeda H, Miyashita N, Nagai H, Imamura Y, Shime N, Suzuki S, Amishima M, Higa F, Kobayashi H, Suga S, Tsutsui K, Kohno S, Brito V, Niederman MS (2019) A therapeutic strategy for all pneumonia patients: a 3-year prospective multicenter cohort study using risk factors for multidrug-resistant pathogens to select initial empiric therapy. Clin Infect Dis 68:1080-1088
4. Aliberti S, Reyes LF, Faverio P, Sotgiu G, Dore S, Rodriguez AH, Soni NJ, Restrepo MI, GLIMP investigators (2016) Global initiative for methicillin-resistant Staphylococcus aureus pneumonia (GLIMP): an international, observational cohort study. Lancet Infect Dis 16:1364-1376

5. Di Pasquale MF, Sotgiu G, Gramegna A, Radovanovic D, Terraneo S, Reyes LF, Rupp J, González Del Castillo J, Blasi F, Aliberti S, Restrepo MI, GLIMP Investigators (2019) Prevalence and etiology of community-acquired pneumonia in immunocompromised patients. Clin Infect Dis 68:1482-1493

6. Mandell LA, Wunderink RG, Anzueto A, Bartlett JG, Campbell GD, Dean NC, Dowell SF, File TM Jr, Musher DM, Niederman MS, Torres A, Whitney CG, Infectious Diseases Society of America; American Thoracic Society (2007) Infectious Diseases Society of America/American Thoracic Society consensus guidelines on the management of community-acquired pneumonia in adults. Clin Infect Dis 44:S27-S72

7. Metlay JP, Waterer GW, Long AC, Anzueto A, Brozek J, Crothers K, Cooley LA, Dean NC, Fine MJ, Flanders SA, Griffin MR, Metersky ML, Musher DM, Restrepo MI, Whitney CG, on behalf of the American Thoracic Society and Infectious Diseases Society of America. Diagnosis and Treatment of Adults with Communityacquired Pneumonia (2019) An official clinical practice guideline of the American Thoracic Society and Infectious Diseases Society of America. Am J Respir Crit Care Med 200:e45-e67

8. Woodhead M, Blasi F, Ewig S, Garau J, Huchon G, Ieven M, Ortqvist A, Schaberg T, Torres A, van der Heijden G, Read R, Verhei TJM, Joint Taskforce of the European Respiratory Society and European Society for Clinical Microbiology and Infectious Diseases (2011) Guidelines for the management of adult lower respiratory tract infections. Clin Microbiol Infect 17:1-24

9. Menendez R, Torres A, Aspa J, Capelastegui A, Prat C, de Castro FR, Community-acquired pneumonia (2010) New guidelines of the Spanish Society of Pulmunology and Thoracic Surgery (SEPAR). Arch Bronconeumol 46:543-558

10. ALAT working group (2004) Update to the Latin American Thoracic Society (ALAT) recommendations on communityacquired pneumonia. Arch Bronconeumol 40:364-374

11. Gupta D, Agarwal R, Aggarwal AN, Singh N, Mishra N, Khilnani GC, Samaria JK, Gaur SN, Jindal SK, for the Pneumonia Guidelines Working Group (2012) Guidelines for diagnosis and management of community- and hospital-acquired pneumonia in adults: joint ICS/NCCP(I) recommendations. Lung India

12. Lim WS, Baudouin SV, George RC, Hill AT, Jamieson C, Le Jeune I, Macfarlane JT, Read RC, Roberts HJ, Levy ML, Wani M, Woodhead MA (2009) BTS guidelines for the management of community acquired pneumonia in adults: update 2009. Thorax 64:iiiliii55

13. Ewig S, Hoffken G, Kern WV, Rohde G, Flick H, Krause R, Ott S, Bauer T, Dalhoff K, Gatermann S, Kolditz M, Kruger S, Lorenz J, Pletz M, de Roux A, Schaaf B, Schaberg T, Schutte H, Welte T (2016) Management of adult community-acquired pneumonia and prevention-update 2016. Pneumologie 70:151-200

14. Pakistan Chest Society (2019) Guidelines for the management of community acquired pneumonia in adults. Available at www. pakistanchestsociety.pk. Accessed 28 Aug 2019

15. Portuguese Respiratory Society (2003) Guidelines for the management of community-acquired pneumonia in immunocompetent adults. Rev Port Pneumol 9:435-461

16. Kuzman I, Civljak R, Puljiz I, Kutlesa M, Topic A, Mazuranic I, Korusic A, Adzic ZO, Brasic B, Samarzija M, Sold D (2017) Guidelines for the management of community-acquired pneumonia in adults. Lijec Vjesn 139:177-191

17. Gadsby NJ, Russel CD, McHugh MP, Mark H, Morris AC, Laurenson IF, Hill AT, Templeton KE (2016) Comprehensive 
molecular testing for respiratory pathogens in community-acquired pneumonia. Clin Infect Dis 62:817-823

18. Jain S, Self WH, Wunderink RG, Fakhran S, Balk R, Bramley AM, Reed C, Grijalva CG, Anderson EJ, Courtney DM, Chappell JD, Qi C, Hart EM, Carroll F, Trabue C, Donnelly HK, Williams DJ, Zhu Y, Arnold SR, Ampofo K, Waterer GW, Levine M, Lindstrom S, Winchell JM, Katz JM, Erdman D, Schneider E, Hicks LA, McCullers JA, Pavia AT, Edwards KM, Finelli L (2015) Community-acquired pneumonia requiring hospitalization among US adults. N Engl J Med 373:415-427

19. Johansson N, Kalin M, Tiveljung-Lindell A, Giske CG, Hedlund J (2010) Etiology of community-acquired pneumonia: increased microbiological yield with new diagnostic methods. Clin Infect Dis 50:202-209

20. Musher DM, Roig IL, Cazares G, Stager CE, Logan N, Safar H (2013) Can an etiologic agent be identified in adults who are hospitalized for community-acquired pneumonia: results of a one-year study. J Inf Secur 67:11-18

21. Bartlett JG (2011) Diagnostic tests for agents of communityacquired pneumonia. Clin Infect Dis 52:S296

22. Carugati M, Aliberti S, Reyes LF, Franco Sadud R, Irfan M, Prat C, Soni NJ, Faverio P, Gori A, Blasi F, Restrepo MI (2018) Microbiological testing of adults hospitalized with communityacquired pneumonia: an international study. ERJ Open Res 4

23. Bjarnason A, Westin J, Lindh M, Andersson LM, Kristinsson KG, Love A, Baldursson O, Gottfredsson M (2018) Incidence, etiology, and outcomes of community-acquired pneumonia: a populationbased study. Open Forum Infect Dis 1

24. Song JH, Oh WS, Kang CI et al (2008) Epidemiology and clinical outcomes of community-acquired pneumonia in adult patients in Asian countries: a prospective study by the Asian network for surveillance of resistant pathogens. Int J Antimicrob Agents 31:107114

25. Shibli F, Chazan B, Nitzan O, Flatau E, Edelstein H, Blondheim O, Raz R, Colodner R (2010) Etiology of community-acquired pneumonia in hospitalized patients in Northern Israel. Isr Med Assoc J $12: 477$
26. Musher DM, Thorner AR (2014) Community-acquired pneumonia. N Engl J Med 371:1619

27. Musher DM (2016) Quantitative molecular approach to diagnosing pneumonia. Clin Infect Dis 62:824

28. Pneumonia Etiology Research for Child Health (PERCH) Study Group (2019) Causes of severe pneumonia requiring hospital admission in children without HIV infection from Africa and Asia: the PERCH multi-country case-control study. Lancet 394:775-779

29. Aston SJ, Ho A, Huwa J, Mitchell T, Ibitoye S, Greenwood S, Joekes E, Daire A, Mallewa J, Everett D, Nyirenda M, Faragher B, Mwandumba HC, Heyderman RS, Gordon SB (2019) Etiology and risk factors for mortality in an adult community-acquired pneumonia cohort in Malawi. Am J Respir Crit Care Med 200:359-369

30. Moran GJ, Krishnadasan A, Gorwitz RJ et al (2012) Prevalence of methicillin-resistant Staphylococcus aureus as an etiology of community-acquired pneumonia. Clin Infect Dis 54:1126

31. Arancibia F, Bauer TT, Ewig S et al (2002) Community-acquired pneumonia due to Gram-negative bacteria and Pseudomonas aeruginosa: incidence, risk, and prognosis. Arch Intern Med 162: 1849

32. Cilloniz C, Ewig S, Polverino E, Marcos MA, Esquinas C, Gabarrus A, Mensa J, Torres A (2011) Microbial aetiology of community-acquired pneumonia and its relation to severity. Thorax 66:340-346

33. Shindo Y, Ito R, Kobayashi D et al (2013) Risk factors for drugresistant pathogens in community-acquired and healthcareassociated pneumonia. Am J Respir Crit Care Med 188:985-995

34. Restrepo MI, Babu BL, Reyes LF, Chalmers JD, Soni NJ, Sibila O, Faverio P, Cilloniz C, Rodriguez-Cintron W, Aliberti S, GLIMP (2018) Burden and risk factors for Pseudomonas aeruginosa community-acquired pneumonia: a multinational point prevalence study of hospitalised patients. Eur Respir J:52

Publisher's note Springer Nature remains neutral with regard to jurisdictional claims in published maps and institutional affiliations. 